\title{
A call for collective crisis leadership
}

\author{
Nobesuthu Ngwenya, Rosalind Helfand, Aylin McNamara, \\ Michelle Cooper, Paola Espinosa, Daniel Flenley, Noa Steiner, \\ Stephen Awoyemi, Iris Dicke, Monipher Musasa and Chris Sandirook
}

Despite nearly 30 years of the United Nations Convention on Biological Diversity (CBD), nature is declining at rates previously unseen in recorded history. Few of the 20 Aichi Biodiversity Targets have been translated into progress (Green et al., 2019). Notwithstanding this poor record, 2020 was billed as the super year for nature and biodiversity. A new deal for nature and people was set to be established through a post-2020 biodiversity framework at the Convention's 15th Conference of the Parties. Then Covid-19 struck. The pandemic has delayed international agreements and actions focused on turning the tide in favour of biodiversity. Environmental protections are already being scaled back, eroding earlier gains and increasing the vulnerability of communities across the globe.

The fragility of our social, economic and political systems has been exposed. We are in crisis: a time of great danger, difficulty or doubt when 'problems must be solved, and important decisions made' (Oxford English Dictionary). The severe, acute eruption of Covid-19 triggered crisis leadership, with sweeping changes implemented. In contrast, biodiversity loss and climate change remain chronic, long-term crises. These less visible-yet ultimately higher-impactcrises have failed to trigger appropriate collective policy responses from world leaders, and continue to worsen.

Understanding the role of leadership in tackling both acute and chronic crises is critical. Within the Covid-19 crisis, a greater understanding is emerging of how governments and society can stand together to improve outcomes for people and planet. If global leaders fail to resolve the root causes of biodiversity loss and climate change-such as our obsession with economic growth (Otero et al., 2020)-they will be left firefighting the manifestations of these crises for decades to come. Here we call for a new approach to pave the way for transformative change.

Nobesuthu Ngwenya*, Rosalind Helfand*, Aylin McNamara*, Michelle Cooper $^{*}$, Paola Espinosa ${ }^{\star}$, Daniel Flenley, Noa Steiner, Stephen Awoyemi, Iris Dicke and MOnipher Musasa University of Cambridge Conservation Leadership Alumni Network

Chris SAndBrook (Corresponding author, (D) orcid.org/0000-0002-9938-4934) Department of Geography, University of Cambridge, Cambridge, UK

E-mail cgs21@cam.ac.uk

${ }^{*}$ Contributed equally

Supplementary material containing details of the University of Cambridge Conservation Alumni Network who are signatories to this call for collective crisis leadership, and a Spanish translation of the Editorial, is available at doi.org/10.1017/S0030605320000496
Existing leadership has proven unable to halt environmental crises as it encourages reactive, top-down decisionmaking, aiming for endless economic growth and often tied to vested interests. This often opaque, partisan leadership style fails to produce shared opportunities to lead change (Pearce, 2004). Leaders may overlook more diverse perspectives, and thus do not tackle the root causes of crises, failing to co-produce solutions with less-powerful groups and limiting the flow of benefits and information.

Although the CBD approach encourages governance through governments, leadership cannot be defined solely by position if transformational change is to occur (Case et al., 2015). All individuals in a society can be leaders and bring about change, by listening, building capacity, and enabling and empowering others.

We believe that a collective approach is critical for tackling the underlying causes of environmental crises and addressing intersectional issues such as inequity, food insecurity, unsustainable supply chains and insufficient family planning. As the Covid-19 pandemic is showing, environmental and social crises are linked at all levels. Collective leadership could generate appropriate, context-specific solutions. Initiatives employing features of collective leadership (Kania \& Kramer, 2013) include the Indigenous Leadership Initiative in Canada (2020), which facilitates socially cross-cutting conservation through collaboration of Indigenous Nations in partnership with Canada's political leadership. Retaining their independence, they cooperate to manage emerging problems adaptively and co-create their future whilst addressing systemic, underlying barriers to social and environmental well-being. Similarly, Cambodia's Sea Turtle Network is a diverse stakeholder collective that has developed a common agenda to guide collective problem-solving. Partners adopt complementary roles, reinforcing each other's activities (Vong et al., 2018). These principles of collective leadership can be scaled up to the global level.

Collective leadership is also essential to overcome systemic socio-economic injustice and biases rooted in racism, which create barriers to addressing environmental crises (Wolff et al., 2016). Indigenous and local communities are first-line defenders of biodiversity and natural resources (Stocking et al., 2014), but strategies for achieving conservation goals are not sufficiently informed by them. The CBD encourages countries to include these groups, but with limited success. To achieve true co-ownership of the post-2020 biodiversity framework, $\mathrm{CBD}$ processes must intrinsically incorporate 
diverse global voices (Sandbrook et al., 2019). Otherwise, the Convention will lose the power of collective impact that comes from enabling 'collective seeing, learning, and doing' (Kania \& Kramer, 2013, p. 6).

Making crisis leadership collective will help overcome the failings of crisis-driven tactics, to deliver true impact and address the urgency and scale of action needed. In this context, we define collective crisis leadership as a systems-based approach to identify and tackle root causes of critical problems through inclusive interdisciplinary thought, decision-making and action across sectors.

The post-2020 biodiversity framework process is a key opportunity to enable collective crisis leadership. As Greta Thunberg (2019, p. 14) said, 'We cannot solve a crisis without treating it as a crisis'. Global, grassroots, student-led protests and declarations of climate emergencies by local governments highlight a growing fear for our shared future. The parties to the CBD must formally acknowledge the urgent nature of the crises, and respond commensurately by aligning mechanisms that support shared goals and milestones to deliver collective impact. This also requires a commitment to stewarding the required network of governments, civil society, communities, grassroots movements, and the private sector to co-produce and test solutions.

Illustrating a collective leadership approach, the University of Cambridge Conservation Leadership Alumni Network is an emerging global network of interdisciplinary conservation leaders across 75 countries working towards the delivery of high-impact initiatives. By harvesting our diverse knowledge and perspectives, over 100 members were involved in an ambitious post-2020 biodiversity framework position submitted to the CBD (UCCLAN, 2020). We call for leadership of a just transition' to protect and restore biodiversity and ecosystems. Specifically, we call on parties to acknowledge the crisis and its root causes, act urgently while leaving no one behind, model policy to reflect social and planetary well-being beyond GDP, and establish accountability mechanisms through transparency and improved communication. As a diverse, decentralized, global network we can support collective crisis leadership processes with the capacity to promote 'reflection, visioning and goal setting, and mutual accountability' (O’Neill \& Brinkerhoff, 2018, p. 35).

The current environmental crises reflect a leadership crisis, the potential impacts of which far outweigh those of the Covid-19 crisis. The pandemic highlights that early action and acknowledgement of a crisis improves outcomes. To scale up conservation efforts, we must accept that our environmental predicament is a crisis and urgently address its chronic underlying causes, not just its symptoms.
We are at a critical moment in history. To move humanity away from inaction, we need an inclusive, enabling approach involving everyone-from health and finance ministers to Indigenous Nations, grassroots organizations, NGOs, businesses and heads of state. Standing alone, we are being set up to fail, constantly firefighting without the resources or opportunities to tackle the source of the blaze. Collectively, we must deal with the root causes of environmental crises. Only then will we see transformational change unfolding, perhaps with more ease than we ever imagined.

\section{References}

Case, P., Evans, L.S., Fabinyi, M., Cohen, P.J., Hicks, C.C., Prideaux, M. \& Mills, D.J. (2015) Rethinking environmental leadership: the social construction of leaders and leadership in discourses of ecological crisis, development, and conservation. Leadership, 11, 396-423.

Green, E.J., Buchanan, G.M., Butchart, S.H., Chandler, G.M., Burgess, N.D., Hill, S.L. \& Gregory, R.D. (2019) Relating characteristics of global biodiversity targets to reported progress. Conservation Biology, 33, 1360-1369.

Indigenous Leadership Initiative (2020) Indigenous-led Conservation. ilinationhood.ca [accessed 10 June 2020].

KANiA, J. \& Kramer, M. (2013) Embracing emergence: how collective impact addresses complexity. Stanford Social Innovation Review, 21 January 2013.

O’Neill, C. \& Brinkerhoff, M. (2018) Five elements of collective leadership. Nonprofit Quarterly, 24, 34-38.

Otero, I., Farrell, K.N, Pueyo, S., Kallis, G., Kehoe, L., Haberl, $\mathrm{H}$. et al. (2020) Biodiversity policy beyond economic growth. Conservation Letters, e12713.

PeArCE, C.L. (2004) The future of leadership: combining vertical and shared leadership to transform knowledge work. Academy of Management Perspectives, 18, 47-57.

Sandbrook, C., Fisher, J.A., Holmes, G., Luque-Lora, R. \& KEANE, A. (2019) The global conservation movement is diverse but not divided. Nature Sustainability, 2, 316-323.

Stocking, M., Perkin, S. \& Brown, K. (2014) Co-existing with nature in a developing world. In People and Nature: Development for the Future (eds. S. Morse \& M. Stocking), pp. 155-186. Routledge, London, UK.

Thunberg, G. (2019) No One is too Small to Make a Difference. Penguin, London, UK.

UCCLAN (University of Cambridge Conservation Leadership Alumni Network) (2020) Post-2020 Global Biodiversity Framework Position, February 2020. Submitted to the CBD Secretariat, OEWG and Focal Points. cbd.int/api/v2013/ documents/6C5F4785-F29o-CF3 E-36CF-26ED917F353D/ attachments/UCCLAN.pdf [accessed 19 May 2020].

Vong, R., TeOH, M. \& West, K. (2018) An action plan for marine turtle conservation in the Kingdom of Cambodia. Oryx, 52, 212.

Wolff, T., Minkler, M., Wolfe, S.M., Berkowitz, B., Bowen, L., Butterfoss, F.D. et al. (2016) Collaborating for equity and justice: moving beyond collective impact. Nonprofit Quarterly, 24, 42-52. 